\title{
HIV/AIDS awareness in schoolgoing adolescents
}

\author{
Tagore V.S. ${ }^{1}$, Kapoor N. ${ }^{2}$
}

${ }^{1}$ Dr. Vinod Singh Tagore, Assistant Professor, ${ }^{2}$ Dr. Nawal Kapoor, Department of Paediatrics, L.N Medical College \& J. K. Hospital, Bhopal, MP, India.

Corresponding Author: Dr. Nawal Kapoor, Assistant Professor, Department of Paediatrics, L.N Medical College \& J.K. Hospital, Bhopal. Email: drnavalkapoor@gmail.com

\begin{abstract}
Objectives: To assess the awareness of school children regarding Human immunodeficiency virus[HIV] to devise strategies or subjects for future programmes and to provide suggestions for school HIV education. Methodology: As about 11 schools were taken in study, 7 were government schools and 4 were Private schools. 7 from the urban areas and 4 from the rural areas. In a school $40-50$ students were surveyed. Total 489 students were divided in different age group i.e. 10-13 year, 14-16 year and 17-19 year, males and females, students were also studied in division of rural and urban group. The students were administered a pre-designed proforma, which included multiple choice questions. Results: In our study 489 students scored $65.4 \%$ in knowledge about disease, 57.5\% in knowledge in complication of disease, $59.9 \%$ in knowledge about prevention of disease, $66.8 \%$ in knowledge about treatment of disease, $48.5 \%$ in knowledge about etiology of disease and $39.1 \%$ in knowledge about medico legal aspect of disease. Conclusion: The study showed tremendous lacunae in awareness of all Reproductive Health (RH) matters. There is a need for evolving information, education, and communication strategies to focus on raising awareness on $\mathrm{RH}$ and gender related issues. A sociocultural research is needed to find the right kind of sexual health services for young girls and boys
\end{abstract}

Key words: Human immunodeficiency virus, Adolescents, Knowledge, awareness

\section{Introduction}

Adolescence is a crucial period for healthy development in both psychological and physical terms. It is a stage of development transition, i.e. a bridge between childhood and adulthood. It is the stage of development of adult mental process and about adult identity and transition from total socioeconomic dependent to relative independent.

The WHO has defined adolescence as:

A. Progression from appearance of secondary sex characteristics (puberty) to sexual and reproductive maturity.

B. Development of adult mental processes and adult identity.

Studies have reported that young people form a significant segment of those attending sexually transmitted infection (STI) clinics and those infected by HIV[1].

Manuscript received: $5^{\text {th }}$ December 2017

Reviewed: $15^{\text {th }}$ December 2017

Author Corrected: $24^{\text {th }}$ December 2017

Accepted for Publication: $28^{\text {th }}$ December 2017
Program managers and policy makers have often recommended that schools can act at the center point for disseminating information and education on HIV/ AIDS. Hence school education has been described as a. social vaccine [2] and it can serve as a powerful preventive tool. In India, there is a wide gap between the inputs in the HIV/AIDS curriculum for schools and the actual education that is imparted [3].

\section{Methodology}

The present study was conducted in department of paediatrics, S.S.M.C. REWA, MP Schools are ideal locations to conduct study on adolescents as they offer the opportunity to access young people of different social and ethnic backgrounds under similar circumstances. As around $10-19$ years of school going children belonging to IX to XII standard were included in study. All students were studying the books of Madhya-Pradesh board and 
medium of study was Hindi in all enrolled Schools. The study was conducted over a period of 4 months from $2^{\text {nd }}$ July 2016 to $30^{\text {th }}$ October 2016. The schools were selected from the different parts of city and rural areas keeping in mind that these schoolsrepresent sample from the different age group, religion, different geographical locations, socio economic and family back grounds.

As many as 11 schools were taken in study, 7 were government schools and 4 were Private schools. 7 from the urban areas and 4 from the rural areasafter explaining the purpose of the study to them and written consent was obtained from their respective principals. The principals were informed earlier about the date of programme and thereafter conveyed to students.
The students were administered a pre-designed profarma, which included multiple choice questions. The response rate of students was 100\%. Question paper was given in presence of teachers to prevent cheating and discussion among students.

The question paper did not include the name of students, so as to make her/him free of pressure of low score. While collecting the filled Proforma it was ensured that entries were complete.

In a school $40-50$ students were surveyed. All 489 students were divided in different age group i.e. 1013 year, 14-16 year and 17-19 year, males and females, students were also studied in division of rural and urban group.

\section{Results}

The present study was conducted in department of pediatrics, S.S.M.C. REWA. In the study 489 students were included in study from both rural and urban schools. The study was done in 4-month course from $2^{\text {nd }}$ July 2014 to $30^{\text {th }}$ October 2014 in government and private schools of Rewa. All 489 students were divided gender, age group and residence.

The students were given a set of questions which shows knowledge about disease, complication of disease, Treatment of disease, Etiology of disease, and attitude and medicolegal aspect of adolescent towards HIV infected patient.

Here, $\mathrm{K} / \mathrm{D}=$ knowledge about disease, which includes question no. 2,3,4,9,10,14,15,18,19,20,21,22,26 and 32

$\begin{array}{lll}\mathrm{K} / \mathrm{C} & = & \text { knowledge about complications, which includes question no. } 5,8 \text { and } 27 \\ \mathrm{~K} / \mathrm{P} & = & \text { knowledge about prevention, Shown by question no.7,13,16,17,23,25,31 } \\ \mathrm{K} / \mathrm{T} & = & \text { knowledge about treatment, Judged by question no.6,24,28,29,30,35 } \\ \mathrm{K} / \mathrm{E} & = & \text { knowledge about etiology, Access by question no. 11,12,33,34 } \\ \mathrm{K} / \mathrm{ML} & = & \text { knowledge about medicolegal aspect, Includes question no. 36,37,38,39 }\end{array}$

And question no. 1 shows where from the adolescent came to know about HIV/AIDS

Table No.-1: Distribution of Specific Knowledge.

\begin{tabular}{|c|c|c|c|c|c|c|}
\hline & $\begin{array}{c}\text { KD knowledge } \\
\text { about disease }\end{array}$ & $\begin{array}{c}\text { KC knowledge } \\
\text { about } \\
\text { complications }\end{array}$ & $\begin{array}{c}\text { knowledge } \\
\text { about } \\
\text { prevention KP }\end{array}$ & $\begin{array}{c}\text { knowledge } \\
\text { about } \\
\text { treatmentKT }\end{array}$ & $\begin{array}{c}\text { knowledge } \\
\text { about } \\
\text { etiologyKE }\end{array}$ & $\begin{array}{c}\text { knowledge about } \\
\text { medicolegal } \\
\text { aspect, KML }\end{array}$ \\
\hline Score & 6846 & 1467 & 3423 & 2934 & 1956 & 1956 \\
\hline Percentage & 65.44 & 57.53 & 59.95 & 66.84 & 48.52 & 39.06 \\
\hline
\end{tabular}

In our study 489 students scored $65.4 \%$ had knowledge about disease, about $57.5 \%$ hadknowledge of complications of disease, About $59.9 \%$ had knowledge about prevention of disease, About $66.8 \%$ had knowledge about treatment of disease, and likewise $48.5 \%$ hadknowledge about etiology of disease and 39.1\% knew about medico legal aspect of disease. 
Table No.-2: Distribution of knowledge on area of residence ground.

\begin{tabular}{|c|c|c|c|c|c|c|c|}
\hline \multirow{2}{*}{ Area } & \multirow{2}{*}{ Total } & KD & KC & KP & KT & KE & KML \\
\cline { 3 - 8 } & & Sum & Sum & Sum & Sum & Sum & Sum \\
\hline Rural & 95 & 861.0 & 142.00 & 415.0 & 410.00 & 203.0 & 141.0 \\
\hline Urban & 394 & 3619.0 & 702.00 & 1637.0 & 1551.00 & 746.0 & 623.0 \\
\hline Total & $\mathbf{4 8 9}$ & $\mathbf{4 4 8 0 . 0}$ & $\mathbf{8 4 4 . 0 0}$ & $\mathbf{2 0 5 2 . 0}$ & $\mathbf{1 9 6 1 . 0 0}$ & $\mathbf{9 4 9 . 0}$ & $\mathbf{7 6 4 . 0}$ \\
\hline
\end{tabular}

In our study there are 95 students belonged to rural areas they scored respectively $64.7 \%$ in $\mathrm{K} / \mathrm{D}, 49.8 \% \mathrm{IN} \mathrm{K} / \mathrm{C}$, $62 \%$ in $\mathrm{KP}, 71.9 \%$ in $\mathrm{K} / \mathrm{T}, 42.7$ in $\mathrm{KE}$, and $37.1 \%$ in medico legal issues while urban their respective scores are $65.5 \%, 59.3 \%, 59.3 \% 65.6 \%, 47.3 \%$ and $39.5 \%$ in $\mathrm{K} / \mathrm{D}, \mathrm{K} / \mathrm{C}, \mathrm{K} / \mathrm{P}, \mathrm{K} / \mathrm{T}, \mathrm{K} / \mathrm{E}$ and $\mathrm{K} / \mathrm{ML}$ respectively so their scores are better than rural participants. Except in preventive measures where rural students are more aware.

Table No.-3: Distribution of knowledge on the basis of mode of first information.

\begin{tabular}{|c|c|c|c|c|c|c|c|}
\hline \multirow{2}{*}{ Mode of knowledge } & \multirow{2}{*}{ Count } & KD & KC & $\mathbf{K P}$ & KT & KE & KML \\
\hline & & $\%$ & $\%$ & $\%$ & $\%$ & $\%$ & $\%$ \\
\hline Books & 141 & 64.7 & 56.0 & 61.2 & 72.9 & 49.3 & 44.0 \\
\hline Family & 1 & 57.1 & 33.3 & 42.9 & 33.3 & 50.0 & 25.0 \\
\hline Friend & 6 & 57.1 & 55.6 & 57.1 & 58.3 & 50.0 & 41.7 \\
\hline Internet & 32 & 62.9 & 55.2 & 55.8 & 64.1 & 47.7 & 42.2 \\
\hline News & 24 & 70.2 & 50.0 & 54.8 & 68.1 & 35.4 & 34.4 \\
\hline Teacher & 89 & 64.9 & 62.5 & 61.0 & 69.3 & 50.8 & 39.9 \\
\hline TV & 195 & 66.2 & 57.8 & 60.1 & 62.0 & 48.7 & 35.1 \\
\hline Total & 489 & 65.4 & 57.5 & 59.9 & 66.8 & 48.5 & 39.1 \\
\hline
\end{tabular}

Most common source of knowledge are television, books and teacher and least common are family, friend and internet.

Table No.-4: Specific knowledge sex wise belonging to rural and urban areas.

\begin{tabular}{|c|c|c|c|c|c|c|c|c|}
\hline \multirow{3}{*}{ Area } & \multirow{2}{*}{ Sex } & \multirow{2}{*}{ Count } & KD (14) & KC (3) & KP (7) & KT (6) & KE (4) & KML (4) \\
\cline { 3 - 9 } & & & Sum & Sum & Sum & Sum & Sum & Sum \\
\hline \multirow{3}{*}{ Rural } & $\mathrm{F}$ & 52 & 480 & 79 & 230 & 223 & 112 & 81 \\
\cline { 2 - 9 } & $\mathrm{M}$ & 43 & 381 & 63 & 185 & 187 & 91 & 60 \\
\cline { 2 - 9 } & Total & 95 & 861 & 142 & 415 & 410 & 203 & 141 \\
\hline \multirow{3}{*}{ Urban } & $\mathrm{F}$ & 91 & 829 & 142 & 374 & 362 & 164 & 148 \\
\cline { 2 - 9 } & $\mathrm{M}$ & 303 & 2790 & 560 & 1263 & 1189 & 582 & 475 \\
\cline { 2 - 9 } & Total & 394 & 3619 & 702 & 1637 & 1551 & 746 & 623 \\
\hline
\end{tabular}

From the above tables, those who came to know about HIV/AIDS from television scored well and higher than any other source of information, Books being the second most common source of knowledge. Only $25.3 \%$ rural adolescent knows about mother to baby transmission while urban adolescent scored $53.3 \%$ only $79 \%$ females knows condom can prevent HIV transmission while $81.8 \%$ males know. In our study we find that females of rural areas scored similar to male of rural and urban as well as females of urban area regarding their knowledge about disease i.e. $69.5 \%, 63.3 \%, 65.8 \%$ and $65.1 \%$ respectively. Knowledge regarding complications of disease males and females of rural areas scored $48.8 \%$ and $50.6 \%$ respectively and of urban males scored $61.6 \%$ and females scored 52\%. Regarding knowledge about prevention rural females scored $63.2 \%$ and males scored $61.5 \%$ while 
urban males and females scored $59.5 \%$ and $58.7 \%$ respectively. In regards to knowledge about treatment rural females and males scored $71.5 \%$ and $72.5 \%$ while of urban areas female scored $66.3 \%$ and $65.4 \%$ respectively. Knowledge regarding etiology rural males scored $52.9 \%$ while female scored $53.8 \%$ in comparison to urban female and male who scored $45.1 \%$ and $48 \%$ respectively Knowledge of rural female and male are $38.9 \%$ and $34.9 \%$ while that of urban are $40.7 \%$ and $39.5 \%$ respectively regarding medicolegal issues.

Statistical Analysis- Data was analyzed using SPSS 20 statistical package. A descriptive analysis was done on all variables to obtain a frequency distribution. The mean + SD and ranges were calculated for quantitative variables. Continuous variables were compared by the Student $t$ test. Proportions were analyzed with the chi-square test. A P value of 0.05 or less was considered statistically significant.

\section{Discussion}

Adolescence is a period of significant growth spurt and maturation. WHO defines adolescence from age $10^{\text {th }}$ to $19^{\text {th }}$ year. In India, different policies and programs define adolescents differently. The Integrated Child Development Services (ICDS) program considers adolescents between 11 to 18 years. Adolescent should be recognized as a special target group for providing health care. They bear the right to have a complete and detailed knowledge and information relating to their development, health and sensitive sexual issues

The study aimed to improve the health awareness, to suggest the sex education and remove the myths and mis-conception about HIV/AIDS. In our study we enrolled 489 adolescent belonging to rural as well as urban areas. The schools were selected from the different parts of city and rural areas keeping in mind that these schools will represent sample from the different age group, religion, different geographical locations, socio economic and family back grounds.

The students were administered a pre-designed proforma, which included multiple choice questions. The response rate of students was 100. While collecting the filled proforma it was ensured that entries were complete. In a school 40 - 50 students were surveyed. Most common source of knowledge are television, books and teacher and least common are family, friend and internet. In our study we found that those students who came to know about HIV/AIDS from books they scored $64.7 \%$ regarding knowledge about disease and 56\% regarding complications similarly $61.2 \%, 72.9 \%, 49.3 \%$ and $44 \%$ marks obtained in knowledge about prevention, treatment, etiology, and medico legalissues. While those who used television as mode of information scored better in all fields excepts $57.8 \%$ in knowledge about complication, $60.1 \%$ in knowledge about prevention, $66.8 \%$ in knowledge about treatment, and $48.7 \%$ in knowledge about etiology and in medicolegal issues they scored $35.1 \%$ which is lesser than knowledge acquired from books.

Similar studywas done by Samkange-Zeeb FN et alwho conducted this systematic review to determine awareness and knowledge of schoolgoing male and female adolescents in Europe of STDs. Results of this reviewhelpedpoint out areas where STD risk communication for adolescents needs to be improved. A total of 15 studies were included in the review. Generally, awareness and knowledge varied among the adolescents depending on gender. Six STDs were focused on in the studies included in the review, with awareness and knowledge being assessed in depth mainly for HIV/AIDS and HPV, and to some extent for chlamydia.

For syphilis, gonorrhoea and herpes only awareness was assessed Despite knowing that use of condoms helps protect against contracting an STD, some adolescents still regard condoms primarily as an interim method of contraception before using the pill. Authors concluded that Sexually transmitted diseases (STDs) are a major health problem affecting mostly young people, not only in developing, but also in developed countries[1].

Gupta N, Mathur AK etal study was planned to test the awareness level of adolescents regarding various reproductive health issues and to identify lacunae in knowledge, particularly in legal minimum age of marriage, number of children, male preference, contraceptive practices, about STIs, AIDS etc. It was a multicentre study, done in rural co-education higher secondary schools of 22 districts located in 14 states through Human Reproductive Research Centre (HRRC's) of the 
Indian Council of Medical Research (ICMR). A sample of 8453 school going adolescents (aged 1019 years) was surveyed by means of open ended, self-administered questionnaires maintaining confidentiality. Awareness of legal minimum age of marriage was present in more than half of adolescents. Attitude towards marriage beyond 21 years in boys and 18 years in girls was favorable. Only $19.8 \%$ of adolescents were aware of at least one method of contraception. Only two-fifth $(39.5 \%)$ were aware of AIDS. And less than onefifth $(18 \%)$ were aware of STDs and most of them thought it is same as AIDS [2].

Esere MO studied theeffect of sex education programme on at-risk sexual behaviour of schoolgoing adolescents in Ilorin, Nigeria.Compared with the control group, this specially designed intervention sex education programme reduced atrisk sexual behaviour in adolescents. Based on this finding, it was recommended that sex education be introduced in Nigerian schools[3].

James S, Reddy SP et al did a cross-sectional study among 1113 grade 11 students in 19 randomly allocated secondary schools. Data were collected through structured questionnaires and analyzed using the SPSS software package.The results confirm that knowledge levels were high for causes and spread of STIs and the participants were well informed about issues relating to protection against STIs and seeking treatment. However, there was significant deviation in reported behaviours.

This discrepancy between awareness and behavior calls for a reorientation of sexuality education to include those elements critical for behavioural change, such as addressing gender discrepancies and promoting skills for communication through planned intervention programmes[4].

In South Africa's HIV/AIDS epidemic, young people, especially women, are at high risk due to an apparent gap between awareness and practice. In repeated peergroup discussions with girls aged 1415 and boys aged 16-19,Harrison A, Xaba N et al explored influences on safe sex behaviour. Separate male and female safe sex paradigms emerged, with boys less likely to perceive themselves as 'at risk' and more likely to use condoms. Girls had not used condoms, would have preferred to delay sexual relationships and feared pregnancy as well as
Original Research Article

HIV/AIDS. Overall, these findings point to the need for programmes to address gender inequalities and emphasizebehavioral skills in the years before sexual activity begins[5].

Two Indian studies Singh A et al regarding awareness of HIV/AIDS among school adolescents in Banaskantha district of Gujarat and otherone by McManus A, Dhar L et al who did study of knowledge, perception and attitude of adolescent girls towards STIs/HIV, safer sex and sex education which was a cross sectional survey of urban adolescent school girls in South Delhi, India. The aim of both the studieswereto evaluate adolescent school girls' knowledge, perceptions and attitudes towards STIs/HIV and safer sex practice and sex education and to explore their current sexual behaviour in India. Though controversial, there is an immense need to implement gender-based sex education regarding STIs, safe sex options and contraceptives in schools in India[6,7].

Despite the fact that adolescents represent almost one quarter of the Indian population, their reproductive health needs are poorly understood and ill served. Jejeebhoy SJ et al documented the existing research on sexual and reproductive health, explored the knowledge and attitudes among this population in India, and highlighted limitations of methodologies currently employed in research on adolescent reproductive health in India. He concluded that what is needed is more behavioral research that explores the levels, patterns, and sociocultural factors underlying adolescents' reproductive health; assesses adolescent reproductive health needs and ways in which health and information services can be structured to respond to these needs in light of the social, cultural and economic constraints that adolescents face; and explores appropriate methodological alternatives, recognizing the need for community-based research, as well as the difficulties of conducting such research under the sociocultural constraints prevailing in India. At the same time, this review argues for far more attention within programs to address adolescent reproductive health service and information needs[8].

Joshi BN, Chauhan SLet aldid a study to assess their reproductive health problems and help seeking behaviour among urban school going adolescents. A sample of 300 urban school going adolescents 
between 11-14 years were chosen at random and assessed using four tools namely, self administered questionnaire: provision of adolescent friendly services; medical screening and focus group discussions.

Their study shows that to increase help seeking behaviour of adolescents, apart from health and life skill education, their medical screening with a focus on reproductive health by trained physicians, parental involvement, supported by adolescent friendly centers (AFC) for counseling, referral and follow up are essential [9]

Srivastava A et alafter theirstudy concludedthat adolescence awareness is a better tool to combat HIV/AIDS. The study showed tremendous lacunae in awareness of all Reproductive Health (RH) matters. There is a need for evolving information, education, and communication strategies to focus on raising awareness on $\mathrm{RH}$ and gender related issues.

A sociocultural research is needed to find the right kind of sexual health services for young girls and boys. Though controversial, there is an immense need to implement gender-based sex education regarding STIs, safe sex options and contraceptives in schools in India[10].

\section{Conclusion}

The most common source of information was television i.e. most accessible. But those who came to know about HIV/AIDS from books have more comprehensive knowledge. The knowledge level are lesser in females of both rural as well as urban areas. Overall rural students have lesser knowledge than urban. The students from the higher standard as well as higher age group have more knowledge and awareness than their following standard and age groups. Awareness is increased in rural areas also shown by comparing from the past studies.

The study showed tremendous lacunae in awareness of all Reproductive Health (RH) matters. There is a need for evolving information, education, and communication strategies to focus on raising awareness on $\mathrm{RH}$ and gender related issues. A sociocultural research is needed to find the right kind of sexual health services for young girls and boys. Though controversial, there is an
Original Research Article

immense need to implement gender-based sex education regarding STIs, safe sex options and contraceptives in schools in India.

Funding: Nil, Conflict of interest: None initiated, Perission from IRB: Yes

\section{References}

1. Samkange-Zeeb FN, Spallek L, Zeeb H. Awareness and knowledge of sexually transmitted diseases (STDs) among school-goingadolescents in Europe: a systematic review of publishedliterature. BMC Public Health. 2011Sep 25; 11:727. doi: 10. 1186/ 1471-2458-11-727.

2. Gupta N, Mathur AK, Singh MP, Saxena NC. Reproductive healthawareness of school-going, unmarried, ruraladolescents. Indian J Pediatr. 2004 Sep; 71(9):797-801.

3. Esere MO. Effect of sex education programme on at-risk sexual behaviour of school-going adolescents in Ilorin, Nigeria. Afr Health Sci. 2008 Jun; 8(2): $120-125$.

4. James S, Reddy SP, Taylor M, Jinabhai CC. Young people, HIV/AIDS/STIs and sexuality in South Africa: the gap between awareness and behaviour. Acta Paediatrica.2004 Feb 1;93(2):264-9.

5. Harrison A, Xaba N, Kunene P. Understanding safe sex: gender narratives of HIV and pregnancy prevention by rural South African school-going youth. Reproductive health matters. 2001 May 1;9 (17): 63-71.

6. Singh A, Jain S. Awareness of HIV/AIDS among school adolescents in Banaskantha district of Gujarat. Health and Population: Perspectives and issues. 2009;32(2):59-65.

7. McManus A, Dhar L. Study of knowledge, perception and attitude of adolescent girls towards STIs/HIV, safer sex and sex education: (a cross sectional survey of urban adolescent school girls in South Delhi, India). BMC women's health. 2008 Jul 23; 8(1): 12 .

8. Jejeebhoy SJ. Adolescent sexual and reproductive behavior: a review of the evidence from India. Social Science \& Medicine. 1998 Mar 20;46(10): 1275-90. 


\section{Original Research Article}

9. Joshi BN, Chauhan SL, Donde UM, Tryambake VH, Gaikwad NS, Bhadoria V. Reproductive healthproblems and help seeking behavior among adolescents in urbanIndia. Indian J Pediatr. 2006 Jun; 73(6):509-13.
10. Srivastava A, Mahmood SE, Mishra P, Shrotriya VP, Shaifali I. Adolescence awareness; a better tool to combat HIV/AIDS. National Journal of Community Medicine. 2011; 2(1): 86-90.

\section{How to cite this article?}

Tagore V.S, Kapoor N. HIV/AIDS awareness in schoolgoing adolescents. Int J Pediatr Res. 2017;4(12):733739.doi:10. 17511/ijpr.2017.i12.06. 